\title{
Contemporary Methods of Construction for Social Deficit in Housing in India
}

\section{R. Sathish Kumar}

\begin{abstract}
In India the housing shortage is much severe with an estimated shortage of around 18 million houses, with $99 \%$ of this is in the economically weaker sections of society. Social housing is the housing system provided for people with low income by government agencies or non-profit organizations. This research paper is about the study of the methods of construction that is adopted in social housing system which will help in improving the social deficit in the housing sector. The study is done with the help of live case studies on housing projects in and around Hyderabad which comes under the flagship programme JNNURM for economically weaker section. The study concluded that the contemporary methods of construction is considered to be advantageous as the government does not provide enough funds for the housing projects and also the contractors are not willing to take any risk and pay for any other modern method of construction.
\end{abstract}

Keywords - Affordable housing, Urbanization, Income level, Slums, Economic backwardness

\section{INTRODUCTION}

$S_{\text {ocial housing is the housing provided for people on }}$ low income or with particular needs, by government agencies or non-profit organizations. For a better economic and social future, the housing system must be efficient so that the living standards and individual sanitation standards will be raised which also reduces the rate of disease in population and mortality. Greater rates of urbanization are experienced with the majority of slums that are located in and around urban centers in the less economically developed countries when compared to more developed countries. Majority of these slums often lack the ability to provide the infrastructure and basic services.

\section{LITERATURE REVIEW}

New York's Chinatown was one of the first slums in United States. While slum clearance did result in a large scale relocation, it also focused on using the cleared-up-land for building more public housing in the area [1]. An alternative to delivering completed houses, is an upgradeable modular house where the foundations and two divisions and a sanitary block is constructed and leaves the home owner to further develop the house. Some of the displaced families were compensated with upgradeable core-houses, in which a family receives a starter-unit with two rooms and the foundations totally built, representing $50 \%$ of a complete house [2]. The factors to be considered in social housing are impact of microfinance lending on quality of life, family budgets and housing quality, links between incentive structures and promotion of equity, comparative studies of land-taxation instruments and contribution to equity,

Revised Manuscript Received on December 30, 2019.

R. Sathish Kumar received Master's degree in Civil Engineering from IIT Madras, Chennai, applicability of international models for rental housing, systematic methodologies for impact analysis of housing interventions and feasibility of strategies for social integration [3]. Many entities in Jamaica both private and public are building houses but the housing need of the poor in Jamaican is not being fulfilled. The cost of labor, materials, land and overall construction are based on market conditions and the idea of providing the poor with a house and a mortgage seems to be contrary to the fact that the poor is challenged by their resources [4]. Glass fibre reinforced gypsum (GFRG) wall panels are used for fast construction and also used as roofing panel's further whole as building systems. GFRG is cheaper than the conventional construction systems without compromising with the strength of the structure.

The slab is constructed by providing T-beams filled by the RCC (reinforced cement concrete). Thus the strength is not compromised at any level of the construction [5]. The main objective of the rental housing scheme is to make available housing stock for an affordable rent. This has been a growing demand for affordable housing for the poor [6].

\section{CASE STUDY}

\subsection{Case Study on Rasoolpura Slum atHyderabad:}

The Rasoolpura slum is one of the largest in Hyderabad with a population of two lakh people and it was designated as a non-notified slum by the government. It is located on the northern part of the city in the Begumpet area, at the Police Lines Cross Road. Estimated age of the slum is close to 60 years. Poor housing conditions, shortage of basic infrastructure, inefficient sewage system and inferior educational facilities are the major drawbacks.
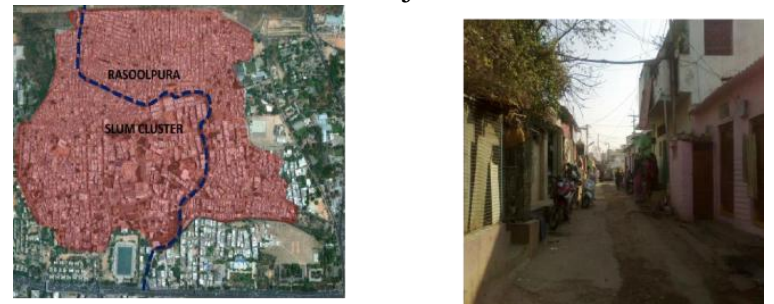

Figure 1. Satellite image of Rasoolpura

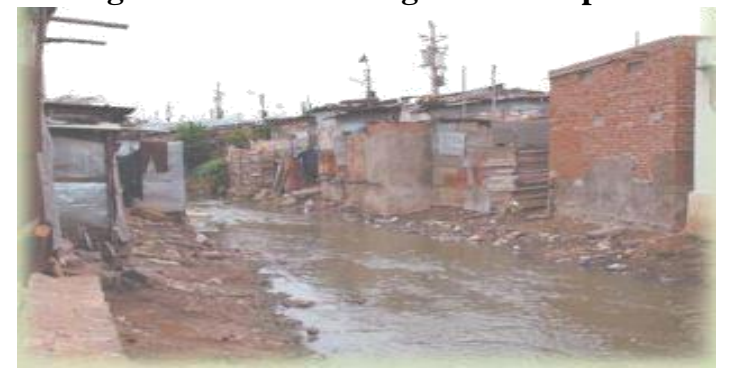

Published By:

Blue Eyes Intelligence Engineering 


\section{Contemporary Methods of Construction for Social Deficit in Housing in India}
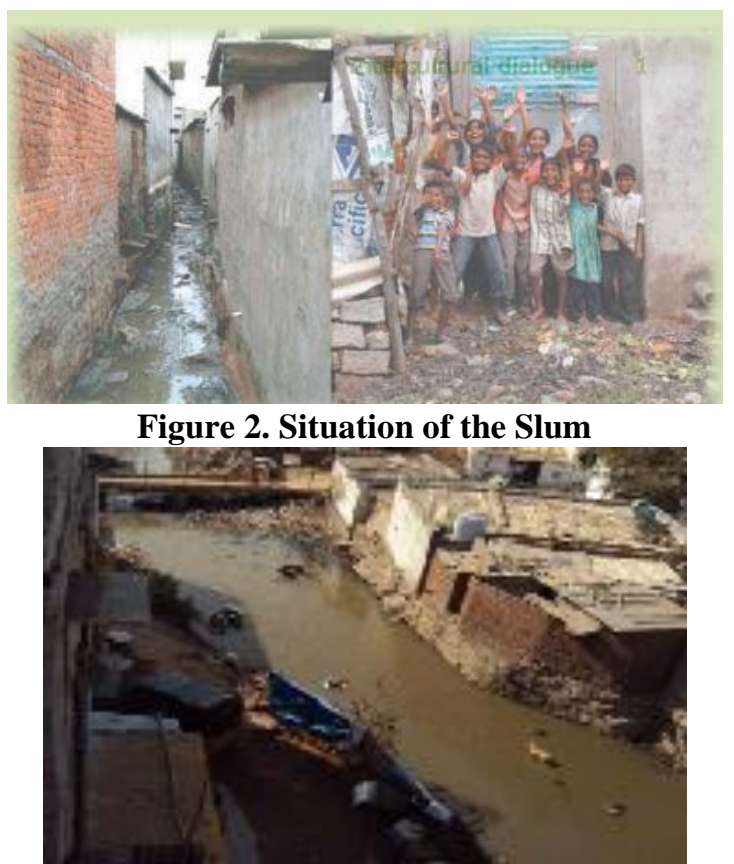

Figure 3. Before development in Rasoolpura slum

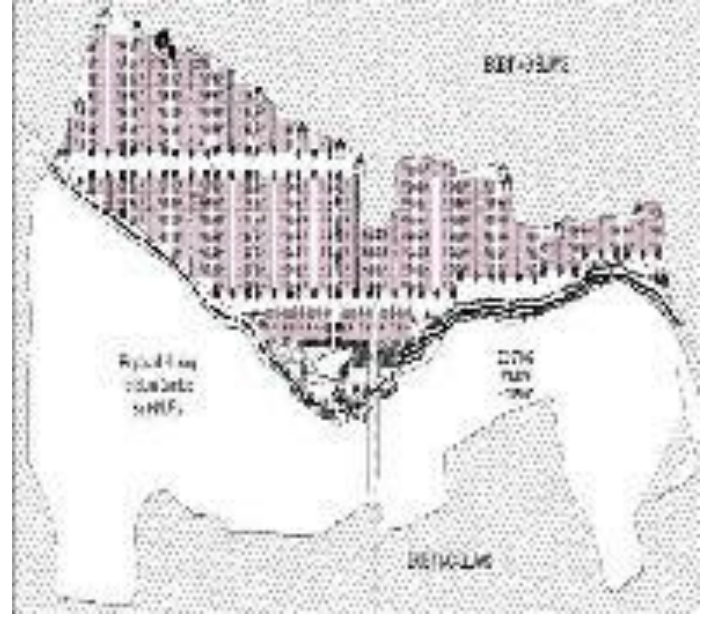

Figure 4. Master plan

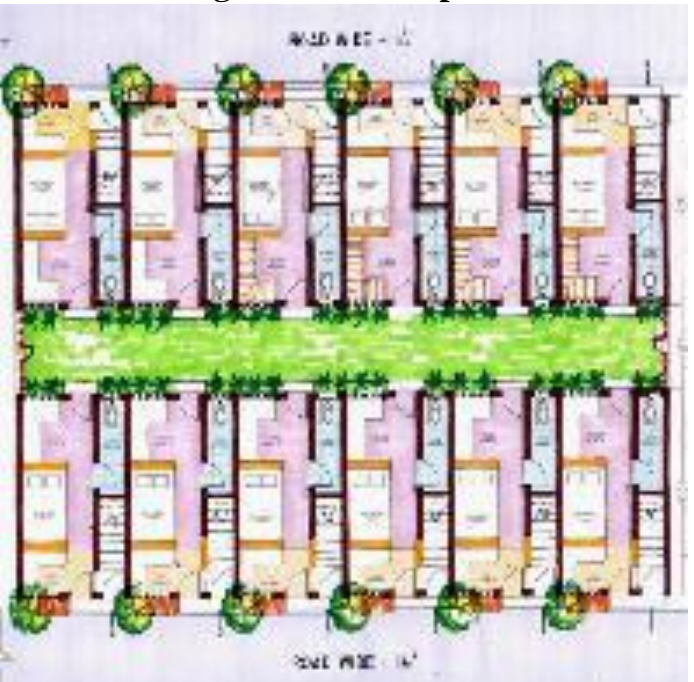

Figure 5. Modified house unit plans in Rasoolpura

Conditions of the Slum before Redevelopment

- $\quad$ All the houses built were kacha in nature

- $\quad$ The width of the streets were varying.

- The slum is filled with domestic and industrial wastes drained from upstream areas as it was situated around a natural stream.
The decks were cleared for the construction of double bedroom houses at Rasoolpura in Secunderabad. The state government has proposed to build 300 two-bedroom houses Officials have completed the survey on the parcel of land to be acquired for the ambitious housing scheme. The land parcel was handed over to the

Greater Hyderabad Municipal Corporation (GHMC) for construction of the houses and GHMC byelaws are followed for construction. A total of 2,160 2-BHK houses were allotted in this area. The land parcel in Rasoolpura belongs to the state government.

C. Redevelopment Plan

a. Type of development : In-situ up gradation of slum

b. Total developed area : 33,600 Sq.M. ( 8.3 Acres )

c. Total number of housing units proposed $(\mathrm{G}+1)$ : 386 Units

d. Total number of housing units existing : 381 SemiPukka +42 Kucha $=423$ Units

D. Features of the Redevelopment Plan

- Regular Grid pattern is followed in layout as it is easier to lay down service pipelines along road edges.

- A 8 feet wide green belt acts as common open spaces for each row of houses.

- The sanitary core utilizes the space below the staircase that results in utilizing the incidental space effectively.

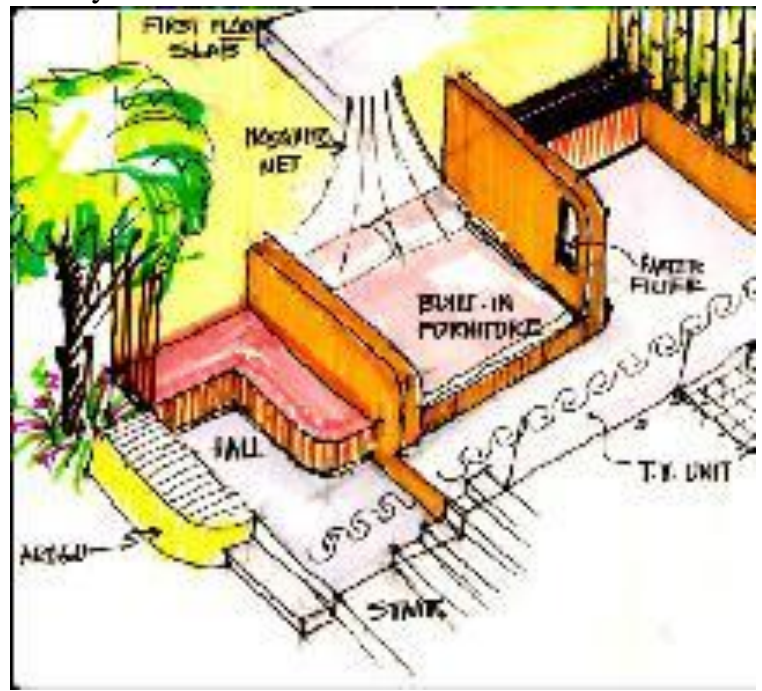

Figure 6. Modified house unit plans in Rasoolpura

E. Construction Materials Adopted

- For the construction of walls hollow block construction technology were adopted. The lighter weight of the blocks made them easier to lift. As large size concrete blocks were used in construction, the number of joints in work got reduced and in turn helped in saving mortar. As the construction material requirement is reduced there was a decrease in construction cost also. Pre cast reinforced cement concrete lintels, RCC (reinforced cement concrete) grill windows and door frames were used in the construction of lintels and frames. Block outs are fixed at vertical panels to provide door, window and ventilation

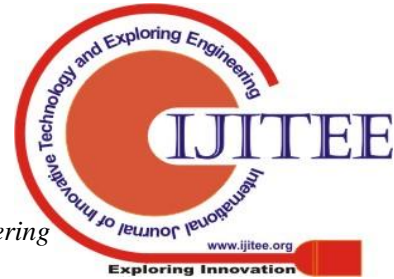


windows in walls for proper day lighting and ventilation. Thickness of the RCC slab $-12 \mathrm{~cm}$. The materials used are as follows.

- Hollow Blocks 6" - 16"x 6"x8"

- Hollow Blocks 4" - 16"x 4"x8"

- RCC Door frames - 3'x 6'6"

- RCC Grill windows - 2'6"x 3'6" and

2'x3'

- Pre-cast RCC lintels - 3'x 0'6”'

\section{F. Case Study on Rampally Village at Hyderabad}

This two bedroom housing scheme ( 2 BHK) is located at Rampally village in Keesaramandal of Hyderabad. This project comes under the GHMC (Greater Hyderabad Housing Corporation). Greater Hyderabad Municipal Corporation (GHMC) for the first time is using the advanced tunnel form technology for the construction of 6,240 houses at Rampally. The civic body is making efforts to complete the construction of the houses at Rampally within one year and the target is to wind up the project by December 2019. Under the conventional method, it would take two years to construct 6,240 houses. The latest construction technology ensured quicker completion of work without compromising on quality and accuracy.

The 6,240 houses at Rampally are being constructed on 41 acres of land at a cost of Rs 541.83 crores. The total area was supposed to have 58 blocks initially but has later been changed to 52 blocks for government approvals. Each block is S+10 Floors (Stilt +10 ). Each floor has 15 Units. So there are a total of 150 Units per block. The stilt area has 124 parking for two

wheelers. Each block has 2 lifts. Another striking aspect about houses at Rampally is that, GHMC is using precast staircase sets for connecting different floors in all the blocks. These sets are being precast at the site and they will be fixed at both ends of a floor in all the blocks. Besides simplifying the entire construction process, the technology enhances the quality and speed of works. The walls are smooth and come with a high quality finish. This technology also provides flexibility in design and layout of the building. The site has a well-equipped Quality lab for all the quality checks and tests and has a batching plant.

G. Technology Used

Tunnel Form construction technique was used for construction. This method of construction achieved time savings up to $25 \%$ with cost savings of $15 \%$. The concrete de-shuttering of the formwork system was done in $16 \mathrm{hrs}$. The successive floors, walls and slab were casted simultaneously. The concrete used was of grade M40. Fly ash was added as an admixture. The foundation for the building was partly raft foundation.

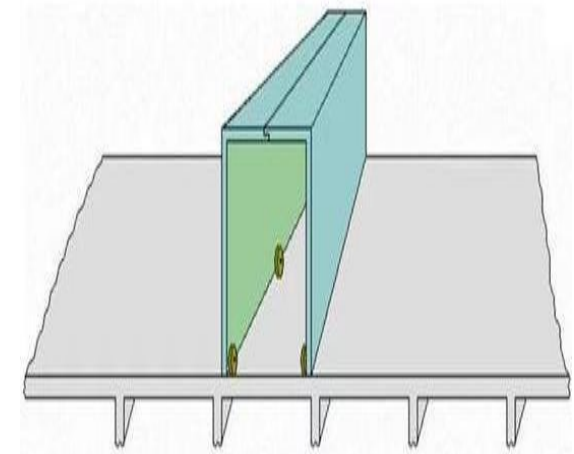

Figure 7. Tunnel formwork - When the two halves are boltedtogether

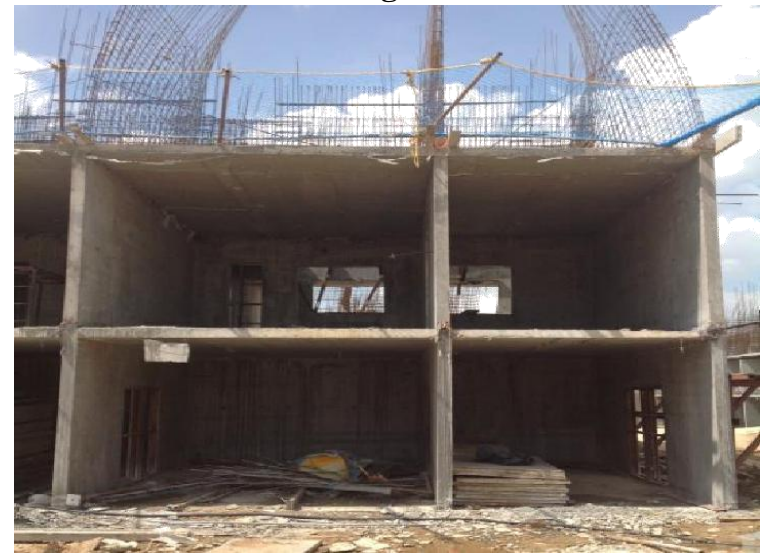

Figure 9. A few glimpses of the site at Rampally
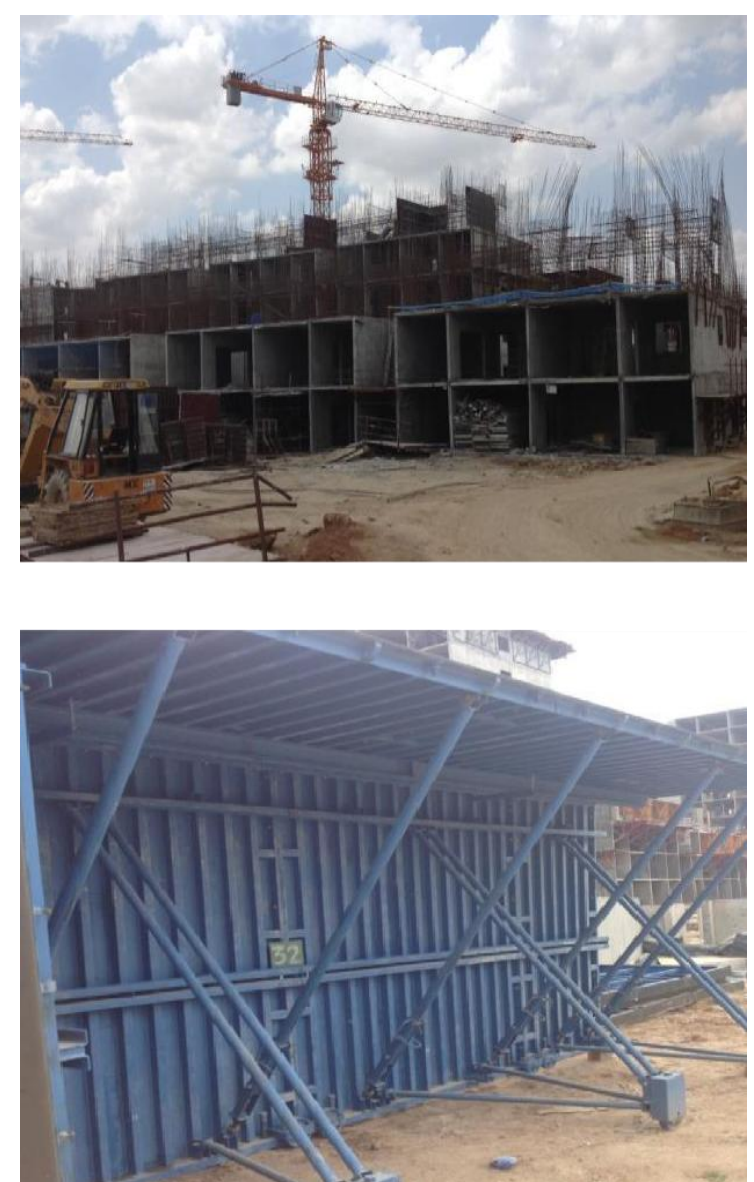

Figure 8. A few glimpses of the site at Rampally 


\section{Contemporary Methods of Construction for Social Deficit in Housing in India}

\section{CONCLUSION:}

The following are the inferences from the case studies

- The type of construction that were adopted for the slum redevelopment in Hyderabad are the contemporary method along with the tunnel form work technology and precast construction method.

- $\quad$ Fast track techniques like tunnel formwork reduced the project duration as compared to the other methods of construction.

- The form work was re-used on other site which is another advantage to the contractor.

- $\quad$ By this technology more number of houses were built in a limited time period without compromising on the quality of construction.

\section{REFERENCES:}

1. Michelle Hindman, Olivia Lu-Hill, Sean Murphy, Sneha Rao, Yash Shah Zeqi Zhu, "Addressingslum redevelopment issues in India, Dow Sustainability Fellowship", 2015.

2. Sara Mc Tarnaghan, Carlos Martín, TanayaSrini, Juan Collazos, "Literature review of housing in Latin America and the Caribbean Phase I", Global Housing Research Initiative. 2016.

3. Grace. A. Daley Williams, "An evaluation of the low-income housing sector in Jamaica", Georgia Institute of Technology. 2006

4. Ron Mahabir, Andrew Crooks, ArieCroitoru , Peggy Agouris, "The study of slums as social and physical constructs: challenges and emerging research opportunities", Regional Studies, Regional Science, 2016.

5. Anindo Sarkar, UdayanDhavalikar, Vikram Agrawal, Sebastian Morris, "Examination of affordable housing policies in India, Indian Institute of Managemen"t, Ahemedabad, 2016

6. Allan Cain, "Understanding market dynamics, performance, and opportunities", Angola'sHousing Sectors, 2016.

7. Y. EmiliusSebastina Antony, "Experimental Investigation on

\section{AUTHORS PROFILE}

R. Sathish Kumar received Master's degree in Civi Engineering from IIT Madras, Chennai, and has been working as Professor in National Institute of Construction Management and Research (NICMAR) Hyderabad, India, since 2009. He has done his Ph D in Masonry Materials and Structures from JNTUH College of Engineering Hyderabad, India. He has published several papers in national journals and conference proceedings. His research interests include sustainable construction materials soil stabilisation., mineral admixtures etc 